\title{
Kinetic and equilibrium modeling for the biosorption of metal ion by Zeolite 13X-Algal- Alginate Beads (ZABs)
}

\begin{abstract}
The potential application of Zeolite 13X-Algal-Alginate Beads (ZABs) for copper biosorption was evaluated and compared with Blank-Alginate Beads (BABs) and Chlorella-Alginate Beads (CABs). Different process parameters were investigated including contact time, $\mathrm{pH}$ and initial metallic ion concentration. The findings indicated that the maximum biosorption capacity of ZABs was $85.88 \mathrm{mg} / \mathrm{g}$ biosorbent achieved at $180 \mathrm{~min}, \mathrm{pH} 5$ and initial metallic ion concentration of $150 \mathrm{mg} / \mathrm{l}$ whereas the maximum capacity of 70.02 and $77.32 \mathrm{mg} / \mathrm{g}$ biosorbent was obtained for BABs and CABs, respectively. ZABs showed higher stability than BABs and $\mathrm{CABs}$ in biosorption-desorption cycles. The kinetic and equilibrium data were analyzed via reaction/diffusion and Langmuir/Freundlich models, respectively. Scanning electron microscopy (SEM), Energy dispersive X-ray spectroscopy (EDX) and Fourier transform infrared spectroscopy (FTIR) indicated bonded metal ion to the ABs. Hence, this study confirmed an improvement in stability and biosorption capacity of microalgal-alginate beads.
\end{abstract}

Keyword: Zeolite 13X; Chlorella; Alginate beads; Biosorption; Kinetic and equilibrium modeling 